\title{
Effect of the p38 MAPK Inhibitor on the Expression of Metalloproteinases and Their Inhibitors during the Formation of Abdominal Adhesions
}

\author{
Irina A. Shurygina, $\mathrm{PhD}, \mathrm{ScD}^{1^{*}}$; Lyubov V. Rodionova, $\mathrm{PhD}^{1}$; Natalia I. Ayushinova, $\mathrm{PhD}, \mathrm{ScD}^{1}$; \\ Elena E. Chepurnykh, $\mathrm{PhD}^{1}$; Irina S. Trukhan, $\mathrm{PhD}^{1}$; Michael G. Shurygin, $\mathrm{PhD}, \mathrm{ScD}^{1,2}$ \\ ${ }^{1}$ Irkutsk Scientific Center of Surgery and Traumatology; ${ }^{2}$ Pharmasyntez \\ Irkutsk, the Russian Federation
}

\begin{abstract}
Background: The aim of this study was to assess the effect of blockade of the p38 mitogen-activated protein kinase (MAPK) on the expression of genes encoding metalloproteinases (MMPs) during the formation of adhesions in the abdominal cavity.

Methods and Results: The experiments were carried out on male Wistar rats $(n=70)$. The studies were carried out in two groups: Group 1 (control, $\mathrm{n}=35$ ) - modelling the adhesive process; Group 2 (experimental, $\mathrm{n}=35$ ) - modelling the adhesive process with intraperitoneal administration of Seroguard ${ }^{\circledR}$ — a prolonged form of the p38 MAPK inhibitor. The expression of the MMPla, $M M P 2, M M P 7, M M P 9$, and TIMP genes was assessed using real-time PCR.

In the control group, overexpression of the MMPla and MMP7 genes began from 6 hours after modeling the adhesive process, $M M P 9$ - from Day 1, MMP2 - from Day 7 and persisted until the end of observation. With local blockade of p38 MAPK, the level of overexpression of genes encoding MMPs in the early stages was higher than in the control group (MMP1a-by Day 1; MMP7 - by 6 hours and Day 1, MMP9 - by 12 hours). From Day 3 to Day 14, the MMP1a and MMP7 expression in the experimental group was significantly lower than in the control group.

Conclusion: The performed study demonstrated the involvement of different types of MMPs - collagenases (MMP1a), gelatinases (MMP2 and 9), matrilysins (MMP7) - in the rearrangement of the extracellular matrix during the process of adhesion formation in the abdominal cavity.(International Journal of Biomedicine. 2021;11(4):446-450.)
\end{abstract}

Key Words: adhesive process $\bullet$ p38 MAPK • MMP • TIMP

For citation: Shurygina IA, Rodionova LV, Ayushinova NI, Chepurnykh EE, Trukhan IS, Shurygin MG. The Effect of the p38 MAPK Inhibitor on the Expression of Metalloproteinases and Their Inhibitors during the Formation of Abdominal Adhesions. International Journal of Biomedicine. 2021;11(4):446-450. doi:10.21103/Article11(4)_OA9

\section{Introduction}

The formation and remodelling of the extracellular matrix are involved in the development of a range of diseases. Matrix metalloproteinases (MMPs) and their inhibitors play an important role in this process. MMPs are classified based on various criteria such as preferred substrate, enzymatic reaction mechanism, soluble or transmembrane domains, and structural homology. ${ }^{(1)}$ Collagenases, gelatinases, stromelysins, matrilysins, membrane-type MMPs, and others are isolated. ${ }^{(2)}$

*Corresponding author: Prof. Irina A. Shurygina, PhD, ScD. Irkutsk Scientific Center of Surgery and Traumatology. Irkutsk, the Russian Federation, E-mail: irinashurygina@gmail.com
For humans, 23 MMPs are known. ${ }^{(3)}$ Collagenases (MMPs $1,8,13,18$ ) are able to break down collagens of types I, II and III. The main substrates of gelatinases (MMPs 2 and 9) are type IV collagen and gelatin. Stromelysins (MMPs 3,10 and 11) have a broad ability to break down extracellular matrix proteins but are unable to split triple-helical fibrillar collagens. Matrilysins (MMPs 7 and 26) break down some components of the extracellular matrix. Membrane-type MMPs (MMPs 14, 15, 16, 17, 24, and 25) are expressed on the cell surface and activate proMMP. Other MMPs not classified in the previous categories include MMPs 12, 19, 20, 21, 23, 27 , and $28{ }^{(2)}$ However, it is becoming more and more obvious that this division is somewhat artificial, since there is a whole range of MMPs that do not fit into any of the traditional groups. 
The catalytic activity of MMPs is regulated by tissue inhibitors of metalloproteinases (TIMPs). ${ }^{(4,5)}$ Traditionally, TIMPs have been thought to control the extracellular matrix by directly inhibiting MMP-dependent proteolysis. This classical role of TIMP suggests that elevated TIMP levels lead to fibrosis, while loss of TIMP leads to increased proteolysis of the matrix. Currently, it is believed that the interaction of MMP and TIMP is much more complex and depends on the specific tissue. ${ }^{(6)}$

The balance between MMP and TIMP levels controls the degree of local degradation of the extracellular matrix at the periphery of cells and thereby influences cellular processes such as migration, proliferation, and survival..$^{(7)}$

MMPs are widely studied in the context of their involvement in extracellular matrix remodelling in acute and chronic diseases of inflammatory genesis. ${ }^{(8)}$ However, at present, their biological functions are being reassessed, which has revealed many unexpected targets for MMPs, including the processing of chemokines, cytokines, and cell surface receptors. ${ }^{(9,10)}$

Considering the role of MMPs in extracellular matrix remodelling, MMPs are the object of study in diseases characterized by excessive growth of connective tissue. MMPs play a complex dual role in the development of fibrosis. MMPs can reduce fibrosis by proteolytic cleavage of extracellular matrix components, but under special circumstances, upregulation of certain MMPs also has an adverse effect that leads to the progression of fibrosis in the liver, lungs, and kidneys. Thus, it has been shown that dysregulation and overexpression of MMPs lead to excessive growth of connective tissue and the formation of rough scars. ${ }^{(11)}$

MMP production is activated in idiopathic pulmonary fibrosis along with inflammatory agents such as TGF- $\beta$ and INF- $\gamma$. The increased levels of expression of MMP9, TIMP1, MMP1 were noted. ${ }^{(12,13)}$ It is believed that increased regulation of MMP1, 2, 10, 11, and 14 is responsible for the progression of fibrosis. ${ }^{(14,15)}$ At the same time, an increase in MMP19 reduces the severity of fibrosis. ${ }^{(16)}$

MMP2, 3, 8, 10, 12, 13, and 14 are significantly increased with liver damage, which, according to some authors, accelerates the process of fibrosis formation. ${ }^{(17,18)}$ Interestingly, an increase in MMP9 expression is associated with both the ability to stimulate development and eliminate fibrosis in the liver. ${ }^{(19)}$ An increase in MMP9 expression in myocardial infarction has been proven. ${ }^{(20,21)}$

The role of MMPs has also been studied in adhesions in the abdominal cavity. It has been shown that the levels of MMP2 and 9 in the blood serum in an experimental model can serve as prognostic markers for the detection of postoperative adhesions. (22) In clinical observation, it was shown that the concentration of MMP9 in the peritoneal fluid was significantly lower in women with adhesions in the pelvis than in healthy women, and the MMP9/TIMP1 ratio was significantly higher in women with significant adhesions during repeated laparoscopy compared with women with minimal adhesions or without adhesions. ${ }^{(23)}$

The aim of this study was to assess the effect of blockade of the p38 mitogen-activated protein kinase (MAPK) on the expression of genes encoding MMPs during the formation of adhesions in the abdominal cavity.

\section{Materials and Methods}

In this study, we used 70 nine-month-old male Wistar rats weighing $220-250 \mathrm{~g}$. The rats were sedated using Ketamine $50 \mathrm{mg} / \mathrm{kg}$, Droperidol $2.5 \mathrm{mg} / \mathrm{kg}$ and Atropine $0.4 \mathrm{mg} / \mathrm{kg}$. An aseptic inflammatory process in the abdominal cavity was simulated by opening the serous-muscular layer of the cecum with a $1 \mathrm{~cm}$ incision, followed by closing the wound using screw sutures and the scarification of the right lateral canal. ${ }^{(24,25)}$

The animals were kept in accordance with good laboratory practice. The experiments were performed in accordance with the norms for the humane treatment of animals, which are regulated by the International Guidelines of the Association for the Assessment and Accreditation of Laboratory Animal Care in accordance with the protocol approved by the Institutional Animal Care and Use Committee of the Irkutsk Scientific Center of Surgery and Traumatology (Protocol No. 6 of 04.18.2017).

The studies were carried out in two groups: Group 1 (control, $\mathrm{n}=35$ ) - modelling the adhesive process; Group 2 (experimental, $\mathrm{n}=35)$ - modelling the adhesive process with administration of Seroguard $\mathbb{B}$ (conjugate the 4-[4-(4-fluorophenyl)-2-(4methylsulfylphenyl)-1H-imidazole-5-pyridine with polyvinylimidazole, JSC "Pharmasyntez") in a volume of $3 \mathrm{ml}$ during the completion of the operation. ${ }^{(26)}$

The animals were sacrificed, and tissues were collected for examination at 7 time points, ranging from 6 hours to 30 days.

The study of gene expression in the serous-muscular layer of the cecum of intact animals $(n=5)$ was used to determine the basic expression of genes.

The samples of the caecum lesion zone were collected from the experimental animals, placed in RNAlater solution (Ambion, Canada, Cat. N 7020), and then crushed in liquid nitrogen. RNA extraction was performed using the RNeasy Mini Kit (Qiagen GmbH, Germany, Cat. N 74104). RNA purification was performed with the Rnase-Free DNase Set (Qiagen GmbH, Germany, Cat. N 79254). cDNA synthesis was performed using the cDNA - RT2 First Strand Kit (Qiagen GmbH, Germany, Cat. N 330401).

The gene expression analysis was performed using realtime polymerase chain reaction (PCR) on a CFX96 Bio Rad device (USA). Gene expression was determined using the RT2-Profiler TM Array Rat Wound Healing Kit (Qiagen GmbH, Germany). The genes are listed in Table 1. We used the RT2 SYBR Green qPCR Mastermix oligonucleotide kit (Qiagen $\mathrm{GmbH}$, Germany, Cat. N 330503). The relative fold difference in gene expression was calculated using the $2^{-\Delta \Delta \mathrm{CT}}$ method.

Table 1.

Genes tested using real-time PCR

\begin{tabular}{|l|l|c|c|}
\hline Notation & \multicolumn{1}{|c|}{ Gene name } & GenBank & Unigene \\
\hline MMP1a & $\begin{array}{l}\text { Matrix metallopeptidase 1a } \\
\text { interstitial collagenase) }\end{array}$ & NM_001134530 & Rn.79007 \\
\hline MMP2 & Matrix metallopeptidase 2 & NM_031054 & Rn.6422 \\
\hline MMP7 & Matrix metallopeptidase 7 & NM_012864 & Rn.10282 \\
\hline MMP9 & Matrix metallopeptidase 9 & NM_031055 & Rn.10209 \\
\hline TIMP1 & $\begin{array}{l}\text { TIMP metallopeptidase } \\
\text { inhibitor 1 }\end{array}$ & NM_053819 & Rn.25754 \\
\hline
\end{tabular}




\section{Results}

We have evaluated the effect of local application of the p38 MAPK inhibitor on the expression of genes encoding metalloproteinases MMP1a, MMP2, MMP7, MMP9, and the TIMP1 inhibitor in the adhesion formation zone. For this purpose, Seroguard $\AA$ was used. It is known that Seroguard $\mathbb{}$ is a prolonged form of the p38 MAPK inhibitor intended for intraperitoneal administration. ${ }^{(26,27)}$

It was found that in the control group, overexpression of the $M M P l a$ and $M M P 7$ genes began as early as 6 hours after modeling the adhesive process, $M M P 9$ - from Day 1, $M M P 2$ - from Day 7 and persisted until the end of observation, indicating the ongoing restructuring of tissues in the damaged zone. The differences were significant with the indices of intact animals for the MMPla and MMP7 genes at all observation periods, for the $M M P 9$ gene - from Day 1 to Day 30, for the $M M P 2$ gene - from Day 7 to Day 30 .

The overexpression of the MMP1a, MMP7 and MMP9 genes has two peaks, on Days 3 and 14, and the overexpression of $M M P 2$ has one peak - on Day 14 (Figure 1).

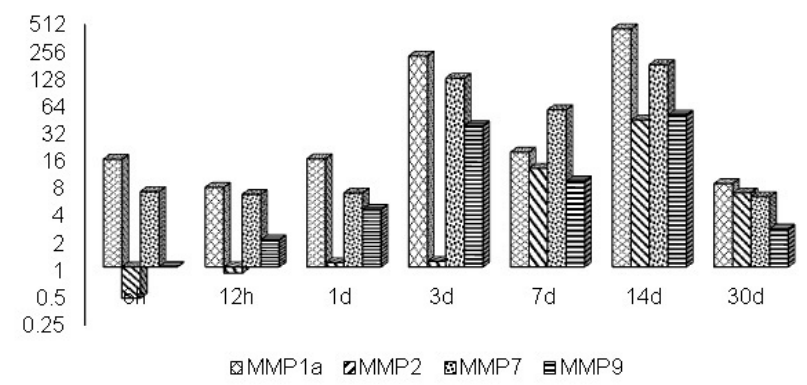

Fig. 1. Expression of genes encoding MMPS in animals of the control group.

In the experimental group, all genes encoding MMPs, except for MMP2 (increased from Day 3), were overexpressed as early as 6 hours after modeling the adhesive process (Figure 2), and gene activity was increased until the end of observation. The differences were significant with the indices of intact animals for all genes encoding MMPs, except for $M M P 2$, at all periods of observation. The first peak of activity for MMP1a falls on Day 1, MMP9 - on Day 3, and $M M P 7$ - on Day 7. The second peak of activity for all genes encoding MMPs is observed on Day 14.

In the experimental group, from 6 hours to a day after injury, the level of overexpression of genes encoding MMPs in the injury zone was higher than in the control group. The differences were significant for MMPla in a period of Day 1, for $M M P 7$ - in a period of 6 hours and Day 1, for $M M P 9$ in a period of 12 hours. From Day 3 to Day 14, the activity of genes encoding MMPs in the experimental group was significantly lower than in the control group. Differences were significant for MMP1a at Day 3 and Day 14, and for $M M P 7$ - at Day 3. However, by the end of the observation (30 days), the expression in the experimental group again exceeds that of the control group. The differences were significant for the $M M P 7$ and $M M P 9$ genes.

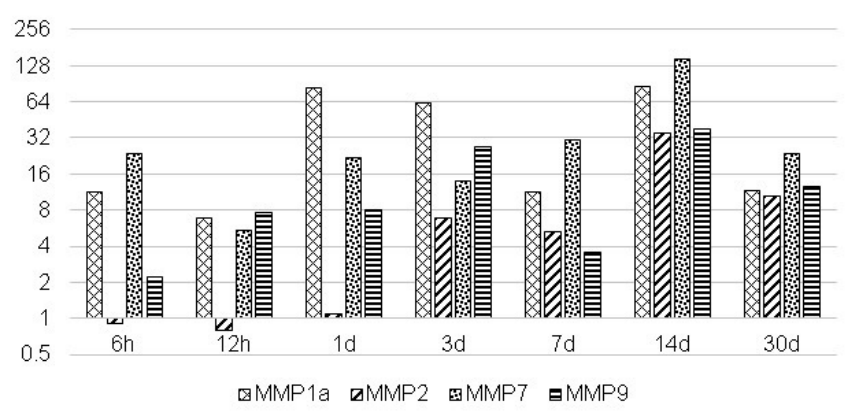

Fig. 2. Expression of genes encoding MMPs in animals of the experimental group.

At the same time, in the experimental group, the expression level of TIMP1 (known as an inhibitor of MMP1) in the early stages (Day 3) was significantly higher than in the control group. In the rest of the periods, no significant differences were found between the groups (Figure 3).

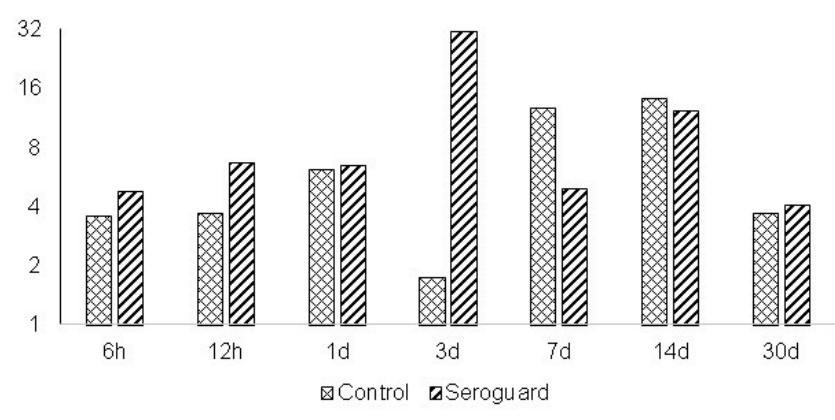

Fig. 3. The TIMPlgene expression in animals of the control and experimental groups.

Interestingly, in animals of the control group, the severity of overexpression of the MMPIa gene was significantly higher than the TIMP1 gene, with the maximum severity of differences on Days 3 and 14 (Figure 4).

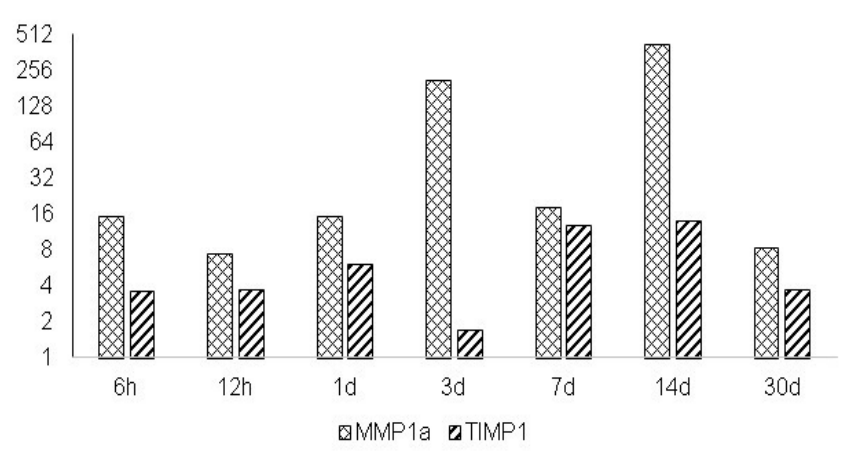

Fig. 4. Expression of the TIMP1 and MMPla genes in animals of the control group. 
In animals of the experimental group, the difference was less pronounced (Figure 5).

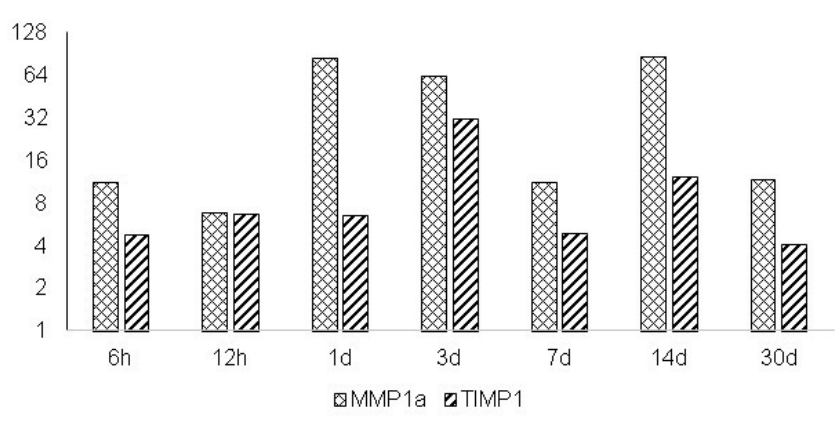

Fig. 5. Expression of TIMP1 and MMP1a in animals of the experimental group.

\section{Conclusion}

The performed study demonstrated the involvement of different types of MMPs - collagenases (MMP1a), gelatinases (MMP2 and MMP9), matrilysins (MMP7)in the rearrangement of the extracellular matrix during the process of adhesion formation in the abdominal cavity. Moreover, the peaks of metalloproteinase activity coincide with the periods of active restructuring and formation of the extracellular matrix and fall on Days 3 and 14 (control group). The overexpression of the $M M P 2$ and $M M P 7$ genes are most pronounced.

Local blockade of p38 MAPK affects the overexpression of MMPs in the peritoneal injury zone, leading to early pronounced overexpression (up to Day 1) of the MMPla, $M M P 7$, and $M M 9$ genes. However, in the control group, the expression of the $M M P 1$ a and $M M P 7$ genes on Days 3 and 14 is higher than in the experimental group with local blockade of $\mathrm{p} 38$ MAPK.

\section{Competing Interests} interests.

The authors declare that they have no competing

\section{References}

1. Cui N, Hu M, Khalil RA. Biochemical and biological attributes of matrix metalloproteinases. Prog Mol Biol Transl Sci. 2017;147:1-73. doi: 10.1016/bs.pmbts.2017.02.005

2. Chen Q, Jin M, Yang F, Zhu J, Xiao Q, Zhang L. Matrix metalloproteinases: inflammatory regulators of cell behaviors in vascular formation and remodeling. Mediators Inflamm. 2013;2013:928315. doi: 10.1155/2013/928315

3. Noel A, Gutierrez-Fernandez A, Sounni NE, Behrendt N, Maquoi E, Lund IK, et al. New and paradoxical roles of matrix metalloproteinases in the tumor microenvironment. Front Pharmacol. 2012;3:140. doi: 10.3389/fphar.2012.00140

4. Khokha R, Murthy A, Weiss A. Metalloproteinases and their natural inhibitors in inflammation and immunity. Nat
Rev Immunol. 2013;13(9):649-65. doi: 10.1038/nri3499 5. Raeeszadeh-Sarmazdeh M, Do LD, Hritz BG. Metalloproteinases and their inhibitors: Potential for the development of new therapeutics. Cells. 2020;9(5):1313. doi: $10.3390 /$ cells 9051313

6. Arpino V, Brock M, Gill SE. The role of TIMPs in regulation of extracellular matrix proteolysis. Matrix Biol. 2015;44-46:247-54. doi: 10.1016/j.matbio.2015.03.005

7. Grunwald B, Schoeps B, Kruger A. Recognizing the molecular multifunctionality and interactome of TIMP1. Trends Cell Biol. 2019;29(1):6-19. doi: 10.1016/j. tcb.2018.08.006

8. Dufour A. Degradomics of matrix metalloproteinases in inflammatory diseases. Front Biosci. 2015;7:150-67. doi: $10.2741 / \mathrm{S} 430$

9. Dufour A, Overall CM. Subtracting matrix out of the equation: New key roles of matrix metalloproteinases in innate immunity and disease. In: Sagi I, Gaffney JP (eds). Matrix metalloproteinase biology. John Wiley \& Sons, Inc.: Hoboken, NJ, USA. 2015;48:131-52. doi: 10.1002/9781118772287.ch8

10. Young D, Das N, Anowai A, Dufour A. Matrix metalloproteases as influencers of the cells' social media. Int J Mol Sci. 2019;20(16):3847. doi: 10.3390/ijms20163847

11. Wynn TA. Cellular and molecular mechanisms of fibrosis. J Pathol. 2008;214(2):199-210. doi: 10.1002/path.2277

12. Yu SH, Liu LJ, Lv B, Che CL, Fan DP, Wang LF, Zhang YM. Inhibition of bleomycin-induced pulmonary fibrosis by bone marrow-derived mesenchymal stem cells might be mediated by decreasing MMP9, TIMP-1, INF- and TGF. Cell Biochem Funct. 2015;33(6):356-66. doi: 10.1002/ cbf.3118

13. Nareznoi D, Konikov-Rozenman J, Petukhov D, Breuer R, Wallach-Dayan SB. Matrix metalloproteinases retain soluble fasL-mediated resistance to cell death in fibroticlung myofibroblasts. Cells. 2020;9(2):411. doi: 10.3390/ cells 9020411

14. Ouchi H, Fujita M, Ikegame S, Ye Q, Inoshima I, Harada E, et al. The role of collagenases in experimental pulmonary fibrosis. Pulm Pharmacol Ther. 2008;21(2):401-8. doi: 10.1016/j.pupt.2007.10.006

15. Mahalanobish S, Saha S, Dutta S, Sil PC. Matrix metalloproteinase: An upcoming therapeutic approach for idiopathic pulmonary fibrosis. Pharm Res. 2020;152:104591. doi: 10.1016/j.phrs.2019.104591

16. Yu GY, Kovkarova-Naumovski E, Jara P, Parwani A, Kass D, Ruiz V, et al. Matrix metalloproteinase-19 is a key regulator of lung fibrosis in mice and humans. Am J Respir Crit Care Med. 2012;186(8):752-62. doi: 10.1164/rccm.2012020302OC

17. Duarte S, Saber J, Fujii T, Coito AJ. Matrix metalloproteinases in liver injury, repair and fibrosis. Matrix Biol. 2015;44-46:147-56. doi: 10.1016/j. matbio.2015.01.004

18. Balog S, Li Y, Ogawa T, Miki T, Saito T, French SW, et al. Development of capsular fibrosis beneath the liver surface in humans and mice. Hepatology. 2020;71(1):291-305. doi: 10.1002/hep.30809

19. Wang Q, Liu X, Zhang J, Lu L, Feng M, Wang J. Dynamic features of liver fibrogenesis and fibrosis resolution in the absence of matrix metalloproteinase-9. Mol Med Rep. 2019;20(6):5239-48. doi: 10.3892/mmr.2019.10740

20. Shurygin MG, Shurygina IA, Dremina NN, Kanya OV. 
[Matrix metalloprotease 9 and remodeling in myocardial infarction]. Byulleten' VSNTs SO RAMN. 2013;90(21):138-41. [Article in Russian].

21. Shurygina IA, Kanya OV, Dremina NN, Shurygin MG. [Pathomorphological assessment method of myocardial infarction age]. Sovremennye Tehnologii v Medicine. 2017;9(2):126-9. doi: 10.17691/stm2017.9.2.15 [Article in Russian].

22. Christodoulidis G, Tsilioni I, Spyridakis ME, Kiropoulos T, Oikonomidi S, Koukoulis G, Tepetes K. Matrix metaloproteinase-2 and -9 serum levels as potential markers of intraperitoneal adhesions. J Invest Surg. 2013;26(3):13440. doi: 10.3109/08941939.2012.730599

23. Cheong YC, Shelton JB, Laird SM, Li TC, Ledger WL, Cooke ID. Peritoneal fluid concentrations of matrix metalloproteinase-9, tissue inhibitor of metalloproteinase-1, and transforming growth factor-beta in women with pelvic adhesions. Fertil Steril. 2003;79(5):1168-75. doi: 10.1016/ s0015-0282(03)00079-7

24. Ayushinova NI, Shurygina IA, Shurygin MG, Lepekhova SA, Balykina AV, Malgataeva ER, et al. [An experimental model for the development of methods for the prevention of adhesions in the abdominal cavity]. Sibirskiy Meditsinskiy Zhurnal. 2012;109(2):51-3. [Article in Russian].

25. Ayushinova NI, Lepekhova SA, Shurygina IA, Roy TA, Shurygin MG, Zaritskaya LV, et al. Method for modeling adhesions in the abdominal cavity: Patent N 2467401 of the Russian Federation. [In Russian].

26. Shurygina IA, Ayushinova NI, Chepurnykh EE, Shurygin MG. [Method for the prevention of adhesions of the abdominal cavity]. Eksperimental'naya i Klinicheskaya Gastroenterologiya. 2017;146(10):83-7. [Article in Russian]. 27. Shurygin MG, Shurygina IA. Compounds, pharmaceutical compositions and a method for the prophylaxis and treatment of the adhesion process: Patent WO/2012/156938 WIPO. 